\title{
mTOR Signalling Pathway-protein Expression in Post-transplant Cutaneous Squamous-cell Carcinomas Before and After Conversion to mTOR-inhibitors
}

\author{
TRIANTAFYLLIA KOLETSA ${ }^{1}$, GEORGIOS PETRAKIS ${ }^{1}$, GEORGIA KARAYANNOPOULOU ${ }^{1}$, \\ SYLVIE EUVRARD ${ }^{2}$ and JEAN KANITAKIS ${ }^{2,3}$ \\ ${ }^{I}$ Department of Pathology, AHEPA Hospital, Aristotelian University of Thessaloniki, Thessaloniki, Greece; \\ ${ }^{2}$ Department of Dermatology, Ed. Herriot Hospital, Lyon, France; \\ ${ }^{3}$ Department of Pathology, Ed. Herriot Hospital, Lyon, France
}

\begin{abstract}
Background/Aim: Inhibitors of the mammalian target of rapamycin (mTORis) exert immunosuppressive and antitumor effects and are used in organ-transplant recipients (OTR) as immunosuppressants able to reduce skin tumor burden. This study investigated the effects of mTORis on the expression of mTOR pathway proteins in cutaneous squamouscell carcinomas (SCC) developing in OTR, before and after switching to mTORis. Materials and Methods: An immunohistochemical study was performed on 23 SCC sections excised from OTR with post-transplant SCC, before or after switch to mTORis, with antibodies against pAkt, pmTOR and PI3K. Results: pmTOR expression was found in 8/12 SCC preswitch, and in 8/11 SCC post-switch, to mTORis. All (but 2) SCC expressed PI3K, and all SCCs expressed pAkt. Conclusion: mTORis do not significantly change the immunohistochemical expression of molecules upstream of the mTOR inhibition (pmTOR, PI3K, pAkt), in cutaneous SCC.
\end{abstract}

The PI3K/Akt/mTOR signalling pathway plays a central role in several cell functions, such as growth, proliferation, survival and motility (1). The mammalian target of rapamycin (mTOR), a 289-kDa serine/threonine protein kinase belonging to the family of phosphatidylinositol-3 kinase (PI3K)-related kinases, is the hub of this signalling pathway, acting both as a downstream effector and upstream regulator, and functions in two complexes, mTOR complex 1 and 2 (mTORC1, mTORC2) (2-4). PI3K, a membrane-associated kinase, is the

Correspondence to: J. Kanitakis, Department of Dermatology, Edouard Herriot Hospital (Pav. R), 69437 Lyon cedex 03, France. Tel: +33 472110301, Fax: +33 472110323, e-mail: jean.kanitakis@univlyon1.fr

Key Words: mTOR signaling, pmTOR, PI3K, pAkt, squamous-cell carcinoma, skin, organ transplant recipients, immunohistochemistry. key molecule upstream of mTOR. Activation of PI3K recruits Akt to the cell membrane, which regulates cell metabolism and mTOR activity (5). Akt is a positive regulator of mTORC1 that phosphorylates and thereby inhibits the heterodimeric tumour-suppressor complex-1 (TSC1/hamartin) and TSC2/tuberin by suppressing its inhibitory effect on mTORC1 (2). mTOR inhibitors (mTORis), including rapamycin/ sirolimus, temsirolimus, everolimus, and ridaforolimus, form an inhibitory complex which binds a region of mTORC1, thereby inhibiting its activity. In addition to its effects on tumour cells, rapamycin also has antiangiogenic activity $(6,7)$, which contributes to its clinical antitumor activity. mTORis are used for the treatment of several types of human cancers, either alone or in combination with other chemotherapeutic agents (8-11). As mTORis have also immunosuppressive properties, they are successfully used in organ transplant recipients (OTR) in order to both prevent allograft rejection and to reduce the rate of skin carcinogenesis (12). Indeed, OTR frequently develop squamous-cell carcinomas (SCC) of the skin as a result of chronic immunosuppression (13). It has been shown that conversion of OTRs from calcineurin-inhibitor-based immunosuppression to mTORis reduces the rate of new cutaneous SCC development (14-18), especially when the switch is introduced early in the process of cutaneous carcinogenesis, i.e. soon after the development of the first skin SCC (18).

The effect of mTORis on molecules involved in the $\mathrm{PI} 3 \mathrm{~K} / \mathrm{Akt} / \mathrm{mTOR}$ pathway has been investigated in some studies using either cell lines or human tumours, but the results have been controversial. Indeed, some studies have found an up-regulation of the molecules upstream of the mTOR inhibition (19-22), whereas other studies (23-25) found opposite results. No relevant study has so far been performed in cutaneous tumours, even though the expression of molecules involved in the mTOR signalling pathway (such as pmTOR) has been previously reported $(26,27)$. The 
Table I. Antibodies used in the study.

\begin{tabular}{lcc}
\hline Antibody & Clone & Provider \\
\hline pmTOR (Ser 2448) & 49F9, code 2976 & Cell Signaling Technology Inc. (Danvers, MA, USA) \\
PI3-kinase, p85a & B-9, code SC-1637 & Santa Cruz Biotechnology (Santa Cruz, CA, USA) \\
p-Akt (Ser 473) & D9E, code 4060 & Cell Signaling Technology Inc. (Danvers, MA, USA) \\
\hline
\end{tabular}

aim of the present study was to investigate the effects of mTORis on the expression of proteins involved in the $\mathrm{PI} 3 \mathrm{~K} / \mathrm{Akt} / \mathrm{mTOR}$ pathway in cutaneous SCC developing in OTR after switching the patients to mTORis-based immunosuppression.

\section{Materials and Methods}

An immunohistochemical study was performed on formalin-fixed, paraffin-embedded specimens of 23 cutaneous SCC retrieved from the files of the Pathology Department, Ed. Herriot Hospital Group, Lyon, France. These tumors had been excised from 10 OTR who had developed post-transplant SCC, and who had been switched to mTORis in order to prevent new carcinoma development, as detailed before (18). The diagnosis of SCC had been confirmed microscopically. Among the 23 cases of SCC studied, $12(52 \%)$ had developed before, and 11 (48\%) had developed after, switching to mTORis. The majority of SCC $(16 / 23,70 \%)$ were well-differentiated, 5 were of moderate differentiation and 2 were of low differentiation. $4-\mu \mathrm{m}$ thick sections from each SCC were immunostained with antibodies to pAkt, pmTOR and PI3K (Table I). Immunohistochemistry was performed by using a standard streptavidin-biotin-immunoperoxidase technique with diaminobenzidine as chromogen and Mayer's hematoxylin as counterstain, as previously described (27). The SCC were considered positive if at least $10 \%$ of tumour cells expressed the molecules examined. Statistical comparison was made with the chi-square test, using the software package SPSS vs. 21. A $p$-value of 0.05 or lower was considered significant.

\section{Results}

The expression of pmTOR was cytoplasmic, with a pericellular/membranous accentuation in many cases (Figure 1A). Positivity for pmTOR was found in 8/12 (67\%) SCC that had developed before, and in 8/11 (73\%) SCC that had developed after, switch to mTORis, this difference being not statistically significant $(p>0.05)$. Eleven out of $16(69 \%)$ pmTOR-positive SCC were well-differentiated and $5(31 \%)$ were poorly or moderately differentiated. Five out of 7 (71\%) pmTOR-negative SCC were well-differentiated. On the whole, pmTOR expression did not show an obvious correlation with tumor differentiation. pAkt immunoreactivity was observed both in the cytoplasm and nucleus (Figure 1B), and PI3K expression was observed in the cell cytoplasm. All SCC cases in both groups (pre- and post-switch) were positive for pAkt, and all (but two - one in each group) were positive for PI3K. No statistically significant differences were found in pAkt and PI3K expression between pre- and post-switch SCC cases $(p>0.05)$.

\section{Discussion}

mTORis are approved for the treatment of several types of human cancers, either alone or in combination with other chemotherapeutic agents (8-10). Everolimus is approved for the treatment of renal cell carcinoma, neuroendocrine pancreatic tumours, hormone receptor-positive, HER2negative breast cancer and giant cell astrocytoma. However, mTORis are not consistently efficient in tumours with PI3K activation such as metastatic breast cancer $(28,29)$, suggesting that mTORis are efficacious in some, but not all, tumours.

The effect of mTORis on molecules involved in the $\mathrm{PI} 3 \mathrm{~K} / \mathrm{Akt} / \mathrm{mTOR}$ pathway has been investigated in some studies using either cell lines or human tumours, but the results have been somewhat controversial. In one study (19) it was found that rapamycin increased the Akt kinase activity in PI3K-hyperactivated tumour cell lines and colon and breast cancers in vivo. Everolimus was reported to increase Akt activity in some, but not all, cell lines from triplenegative breast carcinomas (20). Tabernero et al. (21) found that mTORis upregulated pAkt in $50 \%$ of human advanced solid tumors. Shi et al. (22) observed that mTORis resulted in enhanced Akt activity, phosphorylation and PI3K activity in a myeloma model. Conversely, Li et al. (23) found that mTORis reduced Akt phosphorylation in several cancer cell lines. More recently, it was reported that mTORis decreased the expression of Akt and pmTOR in head and neck cancer cell lines, whereas temsirolimus decreased the activity of pAkt (24). A study using Enzyme-Linked Immunosorbent Assay found that everolimus significantly reduced mTOR expression in head and neck SCC (25). The lack of relevant data in cutaneous carcinomas prompted us to comparatively study the expression of these molecules in SCC developing in the absence of, or under, mTORis. We found that the immunohistochemical expression of molecules involved in the mTOR signaling pathway (pmTOR, PI3K and pAkt) did not differ significantly between SCC developed without or 


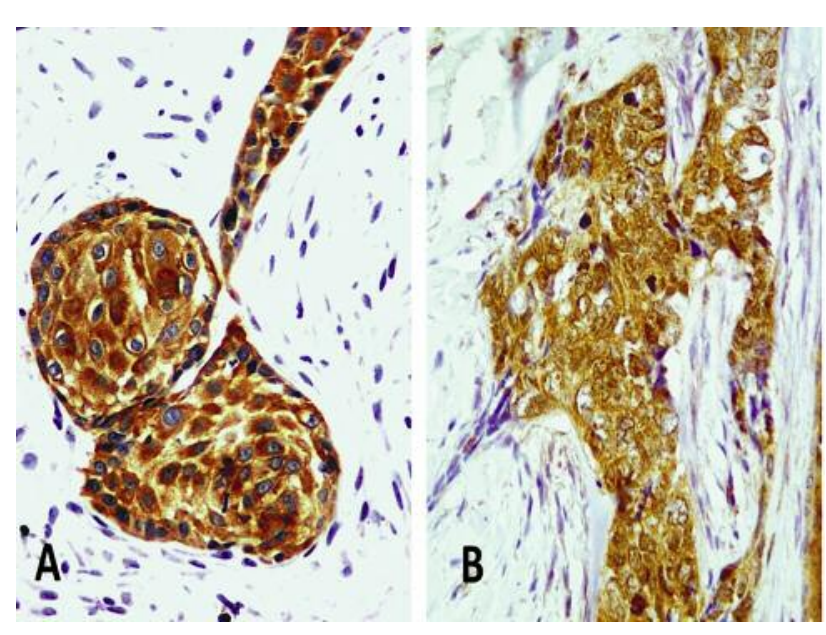

Figure 1. Expression of pmTOR (A) and pAkt (B) in a cutaneous squamous-cell carcinoma (immunoperoxidase revealed with diaminobenzidine, counterstained with Mayer's haematoxylin, original magnification $\times 400)$.

under mTORis-based immunosuppression. Considering that conversion of OTRs to mTORis-based immunosuppression decreases the rate of new SCC development (16), these results suggest that the tumor-preventing effect of mTORis is not necessarily reflected by changes in protein expression, at least at the immunohistochemical level. This is in keeping with the results of a previous study (21), which showed, using immunohistochemistry, that mTORis-induced pAkt upregulation in human advanced solid tumors was not attributable to changes in protein expression. On the other hand, it is likely that even under mTORis-based immunosuppression, the pmTOR pathway remains, at least partly, active; this is consistent with the fact that mTOR is does not totally suppress new SCC development, and also with the possibility that mTOR pathway inhibition could result in activation of other pathways involved in carcinogenesis, such as induction of receptor tyrosine kinase (30), suggesting the need for combination treatments targeting several pathways for a more efficient tumour prevention and management.

In conclusion, our results suggest that mTORis do not significantly alter the expression of molecules upstream of the mTOR inhibition, including pmTOR, PI3K and pAkt, in cutaneous SCC, even though mTORis are clinically effective in reducing the rate of SCC development in OTR receiving mTORis-based immunosuppression. Further studies, namely on molecules downstream of the mTOR inhibition, cellular feedback systems or parallel signalling pathways, will hopefully help unravel the molecular mechanisms whereby mTORis reduce skin carcinogenesis in OTR.

\section{References}

1 Engelman JA: Targeting PI3K signalling in cancer: opportunities, challenges and limitations. Nat Rev Cancer 9: 550-562, 2009.

2 de Fijter JW: Cancer and mTOR Inhibitors in Transplant Recipients. Transplantation 101: 45-55, 2017.

3 Wullschleger S, Loewith R and Hall MN: TOR signalling in growth and metabolism. Cell 124: 471-484, 2006.

4 Fingar D and Blenis J: Target of rapamycin (TOR): An integrator of nutrient and growth factor signals and coordinator of cell growth and cell cycle progression. Oncogene 23: 3151-3171, 2004.

5 Bjornsti MA and Houghton PJ: The TOR pathway: a target for cancer therapy. Nat Rev Cancer 4: 335-348, 2004.

6 Guba M, von BP, Steinbauer M, Koehl G, Flegel S, Hornung M, Bruns CJ, Zuelke C, Farkas S, Anthuber M, Jauch KW and Geissler EK: Rapamycin inhibits primary and metastatic tumor growth by antiangiogenesis: involvement of vascular endothelial growth factor. Nat Med 8: 128-135, 2002.

7 DeYoung MP, Horak P, Sofer A, Sgroi D and Ellisen LW: Hypoxia regulates TSC1/2-mTOR signaling and tumor suppression through REDD1-mediated 14-3-3 shuttling. Genes Dev 22: 239-251, 2008.

8 Alvarado Y, Mita MM, Vemulapalli S, Mahalingam D and Mita AC: Clinical activity of mammalian target of rapamycin inhibitors in solid tumors. Target Oncol 6: 69-94, 2011.

9 Malaguti P, Vari S, Cognetti F and Fabi A: The Mammalian target of rapamycin inhibitors in breast cancer: current evidence and future directions. Anticancer Res 33: 21-28, 2013.

10 Meric-Bernstam F and Gonzalez-Angulo AM: Targeting the mTOR signalling network for cancer therapy. J Clin Oncol 27: 2278-2287, 2009.

11 Dey N, De P and Leyland-Jones B (eds.): PI3K-mTOR in cancer and cancer therapy. Humana Press, 2016.

12 Monaco A: The role of mTOR inhibitors in the management of posttransplant malignancy. Transplantation 87: 157-163, 2009.

13 Euvrard S, Kanitakis J and Claudy A: Skin cancers after organ transplantation. N Engl J Med 348: 1681-1691, 2003.

14 Alberú J, Pascoe MD, Campistol JM, Schena FP, Rial Mdel C, Polinsky M, Neylan JF, Korth-Bradley J, Goldberg-Alberts R and Maller ES: Sirolimus CONVERT Trial Study Group: Lower malignancy rates in renal allograft recipients converted to sirolimus-based, calcineurin inhibitor-free immunotherapy: 24month results from the CONVERT trial. Transplantation 92: 303-310, 2011.

15 Geissler EK: Can immunosuppressive strategies be used to reduce cancer risk in renal transplant patients? Transplant Proc 42(9): S32-35, 2010.

16 Wolf S, Hoffmann VS, Habicht A, Kauke T, Bucher J, Schoenberg M Werner J, Guba M and Andrassy J: mTOR-Is on malignancy and survival following renal transplantation: A systematic review and meta-analysis of randomized trials with a minimum followup of 24 months. PLoS ONE 13(4): e0194975, 2018.

17 Campbell S, Walker R, See Tai S, Jiang Q and Russ G: Randomized controlled trial of sirolimus for renal transplant recipients at high risk for non-melanoma skin cancer. Am J Transplant 12: 1146-1156, 2012.

18 Euvrard S, Morelon E, Rostaing L, Goffin E, Brocard A, Tromme I, Broeders N, del Marmol V, Chatelet V, Dompmartin 
A, Kessler M, Serra AL, Hofbauer GF, Pouteil-Noble C, Campistol JM, Kanitakis J, Roux AS, Decullier E and Dantal J; TUMORAPA Study Group: Sirolimus and secondary skin-cancer prevention in kidney transplantation. N Engl J Med 367: 329$339,2012$.

19 O'Reilly K, Rojo F, She QB, Solit D, Mills G, Smith D, Lane H, Hofmann F, Hicklin D, Ludwig D, Baselga J and Rosen N: mTOR Inhibition Induces Upstream Receptor Tyrosine Kinase Signaling and Activates Akt. Cancer Res 66: 1500-1508, 2006.

20 Yunokawa M, Koizumi F, Kitamura Y, Katanasaka Y, Okamoto N, Kodaira M, Yonemori K, Shimizu C, Ando M, Masutomi K, Yoshida T, Fujiwara Y and Tamura K: Efficacy of everolimus, a novel mTOR inhibitor, against basal-like triple-negative breast cancer cells. Cancer Sci 103: 1665-1671, 2012.

21 Tabernero J, Rojo F, Calvo E, Burris H, Judson I, Hazell K, Martinelli E, Ramon y Cajal S, Jones S, Vidal L, Shand N, Macarulla T, Ramos FJ, Dimitrijevic S, Zoellner U, Tang P, Stumm M, Lane HA, Lebwohl D and Baselga J: Dose- and schedule-dependent inhibition of the mammalian target of rapamycin pathway with everolimus: a phase I tumor pharmacodynamic study in patients with advanced solid tumors. J Clin Oncol 26: 1603-1610, 2008.

22 Shi Y, Yan H, Frost P, Gera J and Lichtenstein A: Mammalian target of rapamycin inhibitors activate the Akt kinase in multiple myeloma cells by up-regulating the insulin-like growth factor receptor/insulin receptor substrate-1/phosphatidylinositol 3kinase cascade. Mol Cancer Ther 4: 1533-1540, 2005.

23 Li Y, Wang X, Yue P, Tao H, Ramalingam SS, Owonikoko TK, Deng $\mathrm{X}$, Wang $\mathrm{Y}, \mathrm{Fu} \mathrm{H}$, Khuri FR and Sun SY: Protein phosphatase 2A and DNA-dependent protein kinase are involved in mediating rapamycin-induced AKT phosphorylation. J Biol Chem 288: 13215-13224, 2013.

24 Borges G, Marques AE and Guerra E: mTOR pathway proteins expression after treatment of head and neck cancer cell lines with mTOR inhibitors. J Cancer Sci Ther 8: 10, 2016.

25 Aderhold C, Faber A, Umbreit C, Birk R, Weiss C, Sommer JU, Hörmann K and Schultz JD: Targeting mTOR and AREG with Everolimus, Sunitinib and Sorafenib in HPV-positive and negative SCC. Anticancer Res 35: 1951-1960, 2015.
26 Gutierrez-Dalmau A, Revuelta I, Ferrer B, Mascaro J, Oppenheimer F, Albanel $\mathrm{J}$ and Campistol J: Distinct immunohistochemical phenotype of nonmelanoma skin cancers between renal transplant and immunocompetent populations. Transplantation 90: 986-992, 2010.

27 Karayannopoulou G, Euvrard S and Kanitakis J: Differential expression of p-mTOR in cutaneous basal and squamous cell carcinomas likely explains their different response to mTOR inhibitors in organ-transplant recipients. Anticancer Res 33: 3711-3714, 2013.

28 Chan S, Scheulen ME, Johnston S, Mross K, Cardoso F, Dittrich C, Eiermann W, Hess D, Morant R, Semiglazov V, Borner M, Salzberg M, Ostapenko V, Illiger HJ, Behringer D, BardyBouxin N, Boni J, Kong S, Cincotta M and Moore L: Phase II study of temsirolimus (CCI-779), a novel inhibitor of mTOR, in heavily pretreated patients with locally advanced or metastatic breast cancer. J Clin Oncol 23: 5314-5322, 2005.

29 Ellard SL, Clemons M, Gelmon KA, Norris B, Kennecke H, Chia S, Pritchard K, Eisen A, Vandenberg T, Taylor M, Sauerbrei E, Mishaeli M, Huntsman D, Walsh W, Olivo M, McIntosh L and Seymour L: Randomized phase II study comparing two schedules of everolimus in patients with recurrent/metastatic breast cancer: NCIC Clinical Trials Group IND.163. J Clin Oncol 27: 4536-4541, 2009.

30 Chandarlapaty S, Sawai A, Scaltriti M, Rodrik-Outmezguine V, Grbovic-Huezo O, Serra V, Majumder PK, Baselga J and Rosen $\mathrm{N}$ : AKT inhibition relieves feedback suppression of receptor tyrosine kinase expression and activity. Cancer Cell 19: 58-71, 2011. 